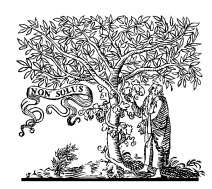

ELSEVIER
Available online at

ScienceDirect

www.sciencedirect.com
Elsevier Masson France

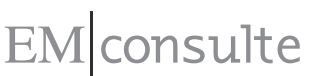

www.em-consulte.com
EUROPEAN

PSYCHIATRY

European Psychiatry 24 (2009) 207-213

Original article

\title{
The individual and societal effects of non-psychotic serious mental disorders on earnings in Belgium
}

\author{
Ronny Bruffaerts*, Anke Bonnewyn, Koen Demyttenaere \\ Department of Neurosciences, University Psychiatric Centre, Katholieke Universiteit Leuven (UPC-KUL), \\ UZ Gasthuisberg, Herestraat 49, B-3000 Leuven, Belgium
}

Received 22 October 2008; received in revised form 11 December 2008; accepted 26 December 2008 Available online 28 March 2009

\begin{abstract}
Purpose. - The purpose of this study is to examine the association between non-psychotic serious mental disorders and earnings in the general population of Belgium on both the individual- and society-level.

Subjects and methods. - Data stem from a cross-sectional population study of the non-institutionalized adult (between 18 and 64 ) population from Belgium $(N=863)$. The third version of the Composite International Diagnostic Interview (CIDI-3.0) was administered to assess 12-month non-psychotic serious mental disorders and annual earnings. Multivariate approaches were used to estimate the observed and estimated annual earnings for persons with serious mental disorders, controlling for sociodemographic variables and alcohol disorders.

Results. - On the individual-level, 12-month serious mental disorders significantly predicted the probability of having any earnings $(\mathrm{OR}=0.32 ; 95 \% \mathrm{CI}=0.14-0.74)$. Respondents with serious mental disorders had 12-month earnings of 5969€ less than expected in the absence of serious mental disorders. Taking into account the prevalence of serious mental disorders (i.e. 4.9\%), the society-level effects of serious mental disorders in 2002 can be estimated at about 1797 million $€$ per year for the Belgian general population.
\end{abstract}

Discussion. - Non-psychotic serious mental disorders had considerable impact on annual earnings.

Conclusion. - This is the first study in Belgium that addresses the association between mental illness and earnings. Serious mental disorders are associated with individual- and societal-level impairments and loss of human capital.

(C) 2009 Published by Elsevier Masson SAS.

Keywords: Mental disorders; Impact; Human capital; Earnings

\section{Introduction}

Epidemiological research on mental disorders systematically yielded consistent findings on the role of mental disorders in the society. A first finding is that mental disorders are common: by-and-large, between 10 and $25 \%$ of the adult general population in western countries meet the criteria for a DSM-IV mental disorder in a given year [12]. A second consistent finding is that these mental disorders have a large impact on the daily life of those who meet the criteria for a disorder. A traditional and often used measure is role functioning or role impairment [8,35]. One major disadvantage of

\footnotetext{
* Corresponding author. Tel.: +32 1634 8728; fax: +32 16348700 .

E-mail address: Ronny.Bruffaerts@med.kuleuven.be (R. Bruffaerts).
}

using role impairment is that it is actually an individual-level measure of impact that provides a valid measure of short-term role impairment. Against the light that mental disorders may have a long-lasting and a societal impact [30], appropriate measures of the impact of mental disorders are strongly needed. Society-level effects of mental disorders can be estimated by their influence on educational attainment [15], or by modelling their effects on income [17]. Especially the effects mental disorders have on earnings are a relatively infrequent albeit interesting measure because the effects of mental disorders on both the individual and society level of productive human capital are estimated. Most research of the effects mental disorders yield on annual earnings stem from the United States. Previous US studies estimated an annual loss of \$44.1 billion in 1985 [33], \$77 billion in 1992 [20], and \$193 
billion in 2002 [25]. Based on the findings from the National Epidemiologic Survey on Alcohol and Related Conditions $(N=43,093)$, income was found to be significantly lower (i.e. between 13 and $16 \%$ ) in persons with suicide attempts [23]. In the National Comorbidity Survey-Replication $(N=4982)$, income was $35-42 \%$ lower for respondents who met the criteria for serious mental disorders [25].

To date, data are still limited in their completeness and comparability. Prior research of the effects of mental disorders on earnings has several limitations. First, most research has been conducted in the United States. There are almost no studies that estimate this influence on a European level. Country-specific estimates might however be important because these may contain concise and detailed implications for policy makers. Second, most (US) studied the effects of mental disorders on earnings in employed versus nonemployed persons, but there were (except one - [25]) no studies that found the influence of mental disorders among employed persons to investigate whether mental disorders may have an influence on the level of earnings. Third, most studies performed in this field have included data that were not representative for a general population.

In this report we use Belgian data from the European Study on the Epidemiology of Mental Disorders (ESEMeD), a part of the World Mental Health surveys (WMH). The WMH surveys are a consortium of general population surveys using a structured psychiatric interview generating DSM-IV disorders. Data were also gathered on the respondents' annual earnings (before taxes). The aims of this study were: (a) to estimate, with advanced statistical methods, the effect of non-psychotic serious mental disorders on annual earnings and (b) to simulate this effect on the societal-level.

\section{Subjects and methods}

\subsection{Subjects}

The European Study on the Epidemiology of Mental Disorders (ESEMeD) is a nationally representative survey that was conducted between April 2001 and June 2002 of the French and Dutch speaking household residents aged 18 or older in Belgium. The initial response rate was $47.5 \%$. In order to increase this moderate rate, $20 \%$ of the initial refusers were re-approached, of which $25.4 \%$ did participate in the study. Weights were applied to these initial refusers to optimize representativity of the study. This conversion resulted in a final response rate of $50.7 \%$. Internal sub-sampling was used to reduce respondent burden and average interview time and cost by dividing the interview into two parts. Part 1 included the core diagnostic assessment of mental disorders $(N=2419)$. Part 2 included questions about correlates and additional mental and physical disorders administered to all part 1 respondents who met the lifetime criteria for any core disorder plus a probability sub-sample of the other respondents $(N=1043)$. Annual earnings were assessed in part 2, but only of respondents between the ages of 18 and $64(N=863)$. Part 2 respondents were weighted by the inverse of their probability of selection for part 2 of the interview to adjust for differential sampling.

\subsection{Methods}

\subsubsection{Training and field procedures}

The central World Mental Health (WMH) staff trained bilingual (Dutch/French) supervisors in each country. The WHO translation protocol was used to translate instruments and training materials [18]. Persons who could not speak Dutch or French were excluded from the fieldwork. Quality control protocols, described in more detail elsewhere [21], were standardized across World Mental Health countries to check on interviewer accuracy and to specify data cleaning and coding procedures. The institutional review board of the organization that coordinated the survey in each country approved and monitored compliance with procedures for obtaining informed consent and protecting human subjects [32].

\subsubsection{Mental disorder assessment}

The survey used the third version of the Composite International Diagnostic Interview (CIDI-3.0) [24], a fully structured diagnostic interview, to assess mental disorders. Field trials and later clinical calibration studies showed that all the disorders considered herein were assessed with acceptable reliability and validity in the original CIDI [36]. The recent clinical reappraisal studies carried out in four WMH countries have provided evidence for a good concordance between CIDI-3.0 diagnoses and diagnoses based on blinded reinterviews, with area under the receiver operator characteristics curve ranging between $0.73-0.93$ for lifetime mood/ anxiety disorders, and $0.83-0.88$ for 12 -month mood/anxiety disorders [19]. Disorders were assessed using the definitions and criteria of the Diagnostic and Statistical Manual of Mental Disorders, fourth edition (DSM-IV) [2]. Serious mental disorders were defined accordingly to criteria stipulated in the Alcohol, Drug Abuse, and Mental Health Administration (ADAMHA) Reorganization Act [27]. We used this classification of "serious mental disorders" instead of "severe and persistent illness" since the number of ESEMeD respondents with severe and persistent mental illness was too small for reliable analysis. "Serious mental disorders" were considerably more prevalent and included severe and persistent mental illness plus either a 12-month suicide attempt with serious lethality intent, an impulse control disorder with repeated serious violence, or any other disorder that resulted in 30 or more days in which the respondent could not carry out daily activities as usual in the 12 months before interview. All other 12-month DSM-IV/CIDI mental disorders were included in a second category, while other lifetime mental disorders constituted a third category. Controls were included for 12month and other lifetime DSM-IV alcohol abuse disorders, with or without dependence.

\subsubsection{Assessment of annual earnings}

Respondents were asked to report their personal earnings in the past 12 months, before taxes. Respondents were instructed 
to count only wages and other stipends from employment (excluding pensions, investments, or other financial assistance). Earnings were divided into quartiles in the sub-sample of respondents who had any earnings to define (i.e. $79.0 \%$ of the sample). The 12-month earning categories used for the Belgian sample were: (a) low earnings (less than $10,000 €$ ), (b) low-average earnings (higher than $10,000 €$ but lower than $15,000 €$ ), (c) high-average earnings (higher than $15,000 €$ and lower than $26,200 €$ ), and (d) high earnings $(>26,200 €)$. We also included an inflation factor of $13.2 \%$ to generate recent estimates. This factor was calculated from an annual mean inflation of 2.09\% in Belgium between 2001 and 2007 [13]. Applying this inflation rate enabled us to adjust our earnings estimates, and thus to provide estimates for 2007.

\subsubsection{Statistics}

Data are provided in numbers $(N)$, weighted proportions $(\%)$, means (M), and standard errors (SE). In order to estimate the effect of serious mental disorders on annual earnings, both logistic regression analysis and general linear models were used. Three analyses were used to elucidate the relationship between serious mental disorders and annual earnings. The first analysis (model 1) estimated the effect of serious mental disorder on annual earnings in the entire sample $(N=863)$, without including other mental disorders as a control variable. The second analysis (model 2) estimated the predictive values of serious mental disorders on having earnings or not among those respondents with serious mental disorders $(N=66)$. The third analysis (model 3) estimated the effect of serious mental disorders on the level of earnings among those respondents with serious mental disorders who reported to have earnings $(N=46)$. General linear models were used for continuous dependent variables (in models 1 and 3); multiple logistic regression was used for the binary dependent variable (of model 2). Results were unadjusted in model 1 and adjusted for the possible influence of age, sex, and alcohol disorders in models 2 and 3.

We used general linear models (GLM) to estimate the effect of serious mental disorders on earnings [25]. To model the effects of mental disorders on the annual earnings properly, GLM was used using pre-specified non-linear relationships and specified error structures to estimate one-part models. GLMs fit highly skewed earnings data better than two-part models $[6,26]$. Simulations yielded two estimates of predicted earnings for each respondent. The first estimate was based on the actual characteristics of the respondent (i.e. meeting criteria for serious mental disorders); the second was based on the counterfactual assumption that none of the respondents had a serious mental disorder. Individual-level differences between these estimates were then averaged across all respondents with serious mental disorders to estimate the mean individual-level decrease in earnings associated with serious mental disorders. Society-level differences were obtained by the estimated prevalence of serious mental disorders and by the size of the non-institutionalized Belgian general population between the ages of 18 and 64. Demographic rate standardization [34] was then used to decompose societal-level estimates into components based on the effects of serious mental disorders on (a) the probability of having any earnings and (b) the effects of mental disorders on the amount earned by respondents with earnings. More details on the statistical methods used to model the effects of serious mental disorders on annual earnings are described elsewhere [25].

\section{Results}

\subsection{Distribution of annual earnings}

The prevalence rates of DSM-IV mental disorders were $4.9 \%$ for 12 -month serious mental disorders, $9.6 \%$ for other 12-month mental disorders, and $13.8 \%$ for other lifetime mental disorders (Table 1). There were no significant gender differences in the distribution of our three mental disorder categories $\left(\chi^{2}=2.09, \mathrm{~ns}\right)$. About eight in 10 respondents (i.e. $79.0 \%$ ) reported any earning in the past 12 months, with significantly more male respondents than female reporting any earning $\left(85.9\right.$ versus $71.2 \%$, respectively; $\chi^{2}=10.15$, $p<0.05$ ). Males were significantly more likely than females

Table 1

Sociodemographic characteristics of the sample.

\begin{tabular}{|c|c|c|c|c|c|c|}
\hline & \multicolumn{2}{|c|}{$\begin{array}{l}\text { Total } \\
(N=863) \\
\%(\mathrm{SE})\end{array}$} & \multicolumn{2}{|c|}{$\begin{array}{l}\text { Male } \\
(N=385) \\
\%(\mathrm{SE})\end{array}$} & \multicolumn{2}{|c|}{$\begin{array}{l}\text { Female } \\
(N=478) \\
\%(\mathrm{SE})\end{array}$} \\
\hline \multicolumn{7}{|l|}{ Mental disorders } \\
\hline 12-month SMI & 4.9 & 1.0 & 4.4 & 1.5 & 5.4 & 1.5 \\
\hline Other 12-month disorders & 9.6 & 1.1 & 8.3 & 1.5 & 10.9 & 1.8 \\
\hline Other lifetime disorders & 13.8 & 1.9 & 10.9 & 1.9 & 16.7 & 2.5 \\
\hline \multicolumn{7}{|l|}{ Annual earnings } \\
\hline Any 12-month earnings & 79.0 & 1.5 & 85.9 & 2.2 & 72.0 & 3.0 \\
\hline \multicolumn{7}{|l|}{ Earning categories } \\
\hline Low earnings & 31.6 & 2.7 & 25.8 & 4.0 & 38.6 & 5.2 \\
\hline Low-average earnings & 15.8 & 1.8 & 15.5 & 2.5 & 16.3 & 2.8 \\
\hline High-average earnings & 37.0 & 2.8 & 35.7 & 2.6 & 38.5 & 5.0 \\
\hline High earnings & 15.6 & 2.3 & 23.0 & 3.8 & 6.6 & 1.7 \\
\hline \multicolumn{7}{|c|}{ Sociodemographic and clinical controls } \\
\hline \multicolumn{7}{|l|}{ Sex } \\
\hline Male & 50.3 & 2.3 & - & - & - & - \\
\hline Female & 49.7 & 2.3 & - & - & - & - \\
\hline \multicolumn{7}{|l|}{ Age } \\
\hline $18-24$ & 13.9 & 1.6 & 14.0 & 3.3 & 13.8 & 3.4 \\
\hline $25-39$ & 35.9 & 2.0 & 33.5 & 2.4 & 38.3 & 3.2 \\
\hline $40-54$ & 34.9 & 2.2 & 35.1 & 4.3 & 34.7 & 3.4 \\
\hline $55-64$ & 15.3 & 1.7 & 17.4 & 2.8 & 13.2 & 1.5 \\
\hline \multicolumn{7}{|l|}{ Alcohol disorder ${ }^{\mathrm{a}}$} \\
\hline Other lifetime dependence & 1.7 & 0.6 & 2.8 & 1.3 & 0.5 & 0.3 \\
\hline 12-month abuse & 1.1 & 0.3 & 1.5 & 0.5 & 0.6 & 0.3 \\
\hline \multicolumn{7}{|l|}{ without dependence } \\
\hline \multicolumn{6}{|l|}{ abuse without dependence } & 1.0 \\
\hline 12-month dependence & 0.6 & 0.3 & 0.5 & 0.4 & 0.7 & 0.5 \\
\hline
\end{tabular}

${ }^{a}$ The four categories of alcohol disorders are mutually exclusive. Respondents with a lifetime history of alcohol dependence who were in partial remission in the 12 months before interview were coded as having 12-month dependence. Only respondents who did not meet the criteria for a 12-month disorder were eligible for classification as having a lifetime disorder. 
to have high earnings ( 23.0 versus $6.6 \% ; \chi^{2}=5.23, p<0.05$ ). Respondents between the ages of 25 and 54 reported the highest earnings, with slightly more male respondents in the highest age category $\left(\chi^{2}=0.41, p<0.05\right)$. Lastly, alcohol disorders were common among male respondents, but this was only the case for lifetime abuse and dependence $\left(\chi^{2}=18.23\right.$, $p<0.05$ and $\chi^{2}=7.85, p<0.05$, respectively) and not for 12-month disorders $\quad\left(\chi^{2}=2.94\right.$, ns and $\chi^{2}=0.10$, ns, respectively).

\subsection{Individual effects of serious mental disorders on earnings}

The first analysis (model 1) estimated the effect of serious mental disorder on annual earnings in the entire sample, without including control variables. This analysis resulted in a non-significant effect of serious mental disorders on earnings ( $\beta=-0.38 ; 95 \% \mathrm{CI}=-0.95$ to $0.20, p=0.19$ ). However, if this analysis was disaggregated by the separate effects of serious mental disorders on having earnings or not (model 2), a different picture emerges. Respondents with serious mental disorders (compared to those without) were significantly less likely to have earnings $(\mathrm{OR}=0.32 ; 95 \% \mathrm{CI}=0.14-0.74$, $p<0.01$ ). A third analysis (model 3) estimated the effect of serious mental disorders on the level of earnings among those who reported to have earnings. Serious mental disorders did not have a significant effect on the level of earnings ( $\beta=-0.06 ; 95 \% \mathrm{CI}=-0.49$ to $0.38, p=0.79)$. This may be due to the lack of power following the small sample of persons with serious mental disorders who declared to have earnings $(N=46)$. Nevertheless, we want to illustrate our estimates of the population impact of serious mental disorders on annual earnings through a comparison of the mean observed and mean expected earnings for both male and female respondents (Table 2). In the sub-sample of respondents with serious mental disorders, the expected annual earnings of respondents approximate (in the absence of serious mental disorders) $15,722 €$, compared with the mean observed earnings of $9748 €$ in those with serious mental disorders. The difference is estimated at $5974 €$ per year or $498 €$ per month (or $37.9 \%$ of the expected earnings), being the estimated effect of serious mental disorders on annual earnings. The effect of serious mental disorders is higher for men (i.e. $9768 €$ per year, or $41.1 \%)$ than for women (2859€ per year, or $31.3 \%$ ). This simulation was repeated among respondents who declared to have earnings. Similarly, we found a difference between the estimated annual earnings for respondents without and with serious mental disorders: 21,207 and $14,117 €$, respectively. Again, the estimated effect of serious mental disorders was higher for male respondents (i.e. $11,085 €$ per year) than for female respondents (i.e. $734 €$ per year).

After applying the mean annual inflation factor in Belgium for the period 2001-2007 (i.e. 2.09\% per year - [13]), we could see that in a simulation for 2007 , the adjusted losses in earnings for persons with serious mental disorders (compared to those without) are about $6763 €$ per year (or $563 €$ per month), with ranges between $3236 €$ for women (or, about $270 €$ per month) and $11,057 €$ for men (or, about $921 €$ per month).

\subsection{Societal effects of serious mental disorders on earnings}

We projected the individual effects to the $6,137,923$ persons aged $20-64$ in the non-institutionalized general population living in Belgium (3,086,142 males and 3,051,781 females) in the time span this survey was performed [14], taking into account the estimated prevalence of 12-month serious mental disorders in Belgium (i.e. $4.9 \%$ for the whole sample; $4.4 \%$ for male and $5.4 \%$ for female respondents). Based on our analyses, the number of Belgian adult inhabitants with serious mental disorders is estimated at approximately 300,758 persons (135,790 males and 164,796 females). The societylevel effects of serious mental disorders were about 1797 million $€$ per year, with markedly higher society-level impact for males (about 1317 million $€$ ) than for females (about 472 million $€)$.

\section{Discussion}

In accordance with studies performed in the United States (e.g. $[17,20,25,33])$, our data suggest that mental disorders are connected with a considerable loss of productive human capital. In this, our findings may add to studies that have shown that mental disorders have a major burden in the society. Most of these studies however did not estimate the effects of mental disorders on a society-level. Compared to the only study that used the same methodological approach [25], we could not find evidence that serious mental disorders resulted in lower earnings among respondents who reported to have earnings at all. As this is the first Belgian study that estimates the impact of serious mental disorders on earnings,

Table 2

Effects of non-psychotic serious mental disorders on the expected and observed annual earnings (in $€$ ) in Belgium, estimates for 2002.

\begin{tabular}{llccc}
\hline & & Total sample M (SE) & Male respondents M (SE) & Female respondents M (SE) \\
\hline All respondents with SMI & Mean observed earnings in $€$ & $9748(1101)$ & $14,022(1430)$ & $6250(791)$ \\
& Mean expected earnings in $€$ & $15,722(1906)$ & $23,790(2426)$ & $9108(1153)$ \\
& Mean estimated impact of SMI in $€$ & $5974(285)$ & $9768(653)$ & $2859(367)$ \\
All respondents with SMI and earnings & Mean observed earnings in $€$ & $14,117(773)$ & $14,886(1336)$ & $12,893(665)$ \\
& Mean expected earnings in $€$ & $21,207(1357)$ & $25,971(2330)$ & $13,628(703)$ \\
& Mean estimated impact of SMI in $€$ & $7090(390)$ & $11,085(556)$ & $734(529)$ \\
\hline
\end{tabular}


we could not rule out whether our findings are a systematic or a more spurious finding. In any case, it is quintessential to acknowledge that mental disorders yield important societal burden. For example, cost-of-illness studies have shown that up to a third of illness-related days may be attributed to the comorbidity of mental disorders [3,29]. Yet, only $6 \%$ of the Belgian health care budget is spent on the treatment of mental disorders [37].

We could not investigate why exactly annual earnings were much lower for persons with serious mental disorders; the precise pathways that link mental illness and lower earnings should be a subject of further investigation. Against this, there are a few plausible explanations. It could be that persons with serious mental disorders were much more unlikely to be employed. To the extent that this is the case, attention should be paid to increased job training or vocational rehabilitation for persons with serious mental disorders. Moreover, supported working programs have been shown to be effective intervention approaches for persons with serious mental disorders [9]. Against the low age of onset of mental disorders in Belgium [5], it is also plausible that serious mental disorders may have adverse effects on adult employment states through their effects on educational attainment [15]. The pathway proposed in the previous study would be that mental disorders may lead to early school termination, that could, in turn, lead to long-lasting decrements in socio-economic situations. Since there are no systematic studies performed in this field, our explanations remain speculative.

The gender differences we found in the study are interesting to discuss. First, while it is generally known that women have a higher likelihood to meet the criteria for 12-month DSM-IV disorders [12], this is not the case for serious mental disorders. Indeed, after applying a severity gradient, the prevalence figures for serious mental disorders are quite similar for men and women. Second, the economic impact of serious mental disorders was higher for men than women. Indeed, we estimated that serious mental disorders were associated with a decreased earning of approximately $270 €$ per month for women, compared to $921 €$ per month for men. Thus, the individual-level impact of serious mental disorders is about three times higher for men than for women. In part, this could be related to the fact that women who meet the criteria for a major depressive episode were less likely to be in the workforce [28]. But this finding may also reflect the gender inequalities in earnings: to date, in the European Union, women are still less likely to have equal earnings as men, even in the same occupational positions [7].

We believe that our estimates of serious mental disorders on annual earnings are somewhat underestimated because of several reasons. First, the instrument we used did not include estimates for a number of mental disorders that are generally known to have more societal impact (e.g. mental disorders due to a medical condition, or psychotic spectrum disorders) than those who were included in the survey. Moreover, the ESEMeD study did not assess persons hospitalized in institutions, incarcerated in prisons, or the homeless. Among these populations, serious mental disorders are estimated in the
$22-33 \%$ range $[20,22]$. Second, there is a bulk of studies that have shown that, not only in clinical but also in general population samples, mental disorders are often comorbid with chronic physical conditions (such as back or neck pain, migraine, or arthritic pain). The comorbidity between 12-month mental disorders and 12-month physical conditions has in Belgium been estimated to be between 43 and $48 \%$ [3]. We believe that, if we would have included these physical conditions in our prediction models, the estimated decrements in annual earnings would have been greater, especially in the light that comorbid pain conditions and mental disorders yielded additional negative effects of role impairment [11].

The results presented here should be interpreted against the following limitations. First, the implications of our results are limited to the disorders included in the analyses. Psychotic disorders were not included in the Belgian version of CIDI-3.0 for reasons of reducing respondent burden. The present analyses may have therefore underestimated the associations between serious mental disorders and earning because we did not examine the possible effects of this group of disorders. For example, persons with psychotic disorders had $27-74 \%$ lower odds to be employed compared to persons without psychotic disorders [31]. But also among those who were employed, psychotic disorders were significantly associated with lower earnings [16]. Second, our data stem from the use of a fullstructured psychiatric interview. This implies that, among others, earnings were assessed using self-reports rather than financial or administrative records. However, the estimates of annual earnings we obtained in this study were quite comparable with the national figures. The mean annual income (after taxes) per Belgian inhabitant (in the 20-64 age range) in the period 1997-2005 was estimated at $9899 €$ [14]. By contrast, in this study the mean annual earning before taxes in the period 2001-2002 approximated 15,147€. If we adjust this income for applicable tax rates in this period [4], the earnings after taxes were estimated in the 9090-10,600€ range, a feature that fits well with the national earnings after taxes (i.e. $9899 €$ ). Third, our data did not allow us to make any causal inference on the association between serious mental disorders and annual earnings, although we may assume that there is a reciprocal effect of low earnings on the risk of mental disorders [10]. Fourth, the response rate of the sample was moderate. Although weighting strategies were used to optimize the representativity of the study, it is plausible that our results were biased because persons with serious mental disorders might have been less likely to participate in this study. Although the prevalence of mental disorders is independent in ESEMeD countries with lower response rates [1], we could not rule out that the low response rates may have biased the association between serious mental disorders and earnings. May be the most important limitation, the fifth, pertains to the relatively small response rate. Our estimations of differences in earnings were based on a sample of 66 persons who met the criteria for serious mental disorders and 797 persons without serious mental disorders. Indeed, we should stress that our results are more likely indicative of the associations between serious mental disorders and earning. 
The sums of the loss of earnings on the national level should therefore be interpreted as an indication and first estimate of the differences in earnings than definite facts. It is evident that our estimates should be refuted, confirmed, or refined in further studies.

\section{Conclusion}

From this first Belgian study investigating the relationship between serious mental disorders and annual earnings, three main findings stand out. First, serious mental disorders were associated with significant decreased odds of having any annual earnings but not with having lower earnings. Second, the decrease of annual earnings in persons with serious mental disorders is estimated to be about $38 \%$, with marked differences between male and female respondents. Third, on the level of the Belgian general adult population (younger than $65)$, serious mental disorders were associated with a loss of approximately 1800 million $€$ in personal earnings per year.

\section{Acknowledgments}

The ESEMeD survey was carried out in conjunction with the World Health Organization World Mental Health (WMH) survey initiative. We thank the WMH staff for assistance with instrumentation, fieldwork, and data analysis. These activities were supported by the United States National Institute of Mental Health (R01MH070884), the John D and Catherine T MacArthur Foundation, the Pfizer Foundation, the US Public Health Service (R13-MH066849, R01MH069864, and R01 DA016558), the Fogarty International Center (FIRCA R01-TW006481), the Pan American Health Organization, Eli Lilly and Company, Ortho-McNeil Pharmaceutical, Inc., GlaxoSmithKline, and Bristol-Myers Squibb. A complete list of WMH publications can be found at http://www.hcp.med.harvard.edu/wmh. The ESEMeD project is funded by the European Commission (contracts QLG5-1999-01042; SANCO 2004123), the Piedmont Region (Italy), Fondo de Investigación Sanitaria, Instituto de Salud Carlos III, Spain (FIS 00/0028), Ministerio de Ciencia y Tecnología, Spain (SAF 2000-158-CE), Departament de Salut, Generalitat de Catalunya, Spain, and other local agencies and by an unrestricted educational grant from GlaxoSmithKline (GSK). Between 2000 and 2005, the study in Belgium was entirely sponsored by an unrestricted educational grant from GSK, whereas from 2005 onwards the study was sponsored by both GSK and the European Union (contract SANCO 2004123).

\section{References}

[1] Alonso J, Angermeyer M, Bernert S, Bruffaerts R, Brugha TS, Bryson H, et al. Prevalence of mental disorders in Europe: results from the European Study of the Epidemiology of Mental Disorders (ESEMeD) project. Acta Psychiatrica Scandinavica 2004;109(Suppl. 420):21-7.

[2] American Psychiatric Association. DSM-IV: diagnostic and statistical manual of mental disorders. 4th ed. Washington, DC: American Psychiatric Association; 1994.
[3] Bertrem CH, Bruffaerts R, Bonnewyn A, Van Oyen H, Demarest S, Demyttenaere K. Mental and pain comorbidity of chronic somatic disorders in the general population of Belgium. Archives of Public Health 2006;64:199-214.

[4] Blomme J. Internationale vergelijking van de belasting op het loon. België, Nederland, Frankrijk, Duitsland en Spanje. Inkomsten van het jaar 2000. Documentatieblad Federale Overheidsdienst Financiën 2003; 63:1-50.

[5] Bonnewyn A, Bruffaerts R, Vilagut G, Almansa J, Demyttenaere K. Lifetime risk of mental disorders in the Belgian general population. Social Psychiatry and Psychiatric Epidemiology 2007;42:522-9.

[6] Buntin MB, Zaslavsky AM. Too much ado about two-part models and transformation? Comparing methods of modelling Medicare expenditures. Journal of Health Economics 2004;23:525-42.

[7] Burchell B, Fagan C, O'Brien C, Smith M. Working conditions in the European Union: the gender perspective. Luxembourg: Office for Official Publications of the European Communities; 2007.

[8] Chwastiak LA, Von Korff M. Disability in depression and back pain: evaluation of the World Health Organization Disability Assessment Schedule (WHO DAS II) in a primary care setting. Journal of Clinical Epidemiology 2003;56:507-14.

[9] Cook JA, Lehman AF, Drake R, McFarlane WR, Gold PB, Leff HS, et al. Integration of psychiatric and vocational services: a multisite randomized, controlled trial of supported employment. American Journal of Psychiatry 2005;10:1948-56.

[10] Costello EG, Compton SN, Keeler G, Angold A. Relationships between poverty and psychopathology: a natural experiment. Journal of the American Medical Association 2003;290:2023-9.

[11] Demyttenaere K, Bonnewyn A, Bruffaerts R, Brugha T, De Graaf R, Alonso J. Comorbid painful physical symptoms and depression: prevalence, work loss, and help seeking. Journal of Affective Disorders 2006; 92:185-93.

[12] Demyttenaere K, Bruffaerts R, Posada-Villa J, Gasquet I, Kovess V, Lepine JP, et al. Prevalence, severity and unmet need for treatment of mental disorders in the World Health Organization World Mental Health (WMH) surveys. Journal of the American Medical Association 2004; 291:2581-90.

[13] Federale Overheidsdienst Economie, KMO, Middenstand en Energie. Inflatiecijfers en vooruitzichten. Brussel: Algemene Directie Statistiek en Economische Informatie, http://statbel.fgov.be/indicators/cpi/infl_nl.asp; 2008 [accessed October 13, 2008].

[14] Federale Overheidsdienst Economie, KMO, Middenstand en Energie. Structuur van de bevolking. Brussel: Algemene Directie Statistiek en Economische Informatie, http://www.statbel.fgov.be/figures/d21_nl.asp\#3; 2008 [accessed October 11, 2008].

[15] Freudenberg N, Ruglis J. Reframing school dropout as a public health issue. Preventing Chronic Disease 2007;4. A107.

[16] Goeree R, Farahati F, Burke N, Blackhouse G, O'Reilly D, Pyne J, et al. The economic burden of schizophrenia in Canada in 2004. Current Medical Research and Opinion 2005;21:2017-28.

[17] Goldsmith AH, Veam JR, Darity W. The impact of psychological and human capital on wages. Economic Inquiry 1997;35:815-29.

[18] Harkness J, Pennell BE, Villar A, Gebler N, Aguilar-Gaxiola S, Bilgen I. Translation procedures and translation assessment in the World Mental Health survey initiative. In: Kessler RC, Üstün TB, editors. The WHO World Mental Health surveys: global perspectives on the epidemiology of mental disorders. New York, NY: Cambridge University Press; 2008.

[19] Haro JM, Arbabzadeh-Bouchez S, Brugha TS, de Girolamo G, Guyer ME, Jin R, et al. Concordance of the Composite International Diagnostic Interview version 3.0 (CIDI 3.0) with standardized clinical assessments in the WHO World Mental Health surveys. International Journal of Methods in Psychiatric Research 2006;15:167-80.

[20] Harwood H, Ameen A, Denmead G, Englert E, Fountain D, Livermore G. The economic cost of mental illness, 1992. Rockville, MD: National Institute of Mental Health; 2000.

[21] Heeringa SG, Wells J, Hubbard F, Mneimneh Z, Chiu WT, Sampson N, et al. Sample designs and sampling procedures. In: Kessler RC, 
Üstün TB, editors. The World Mental Health survey initiative: patterns of mental illness in the WMH surveys, vol. 1. New York: Cambridge University Press; 2008. p. 14-32.

[22] James DJ, Glaze LE. Bureau of Justice Statistics special report: mental health problems of prison and jail inmates. Washington, DC: U.S. Department of Justice, Office of Justice Programs; 2006.

[23] Kalist DE, Molinari NA, Siahaan F. Income, employment and suicidal behaviour. Journal of Mental Health Policy and Economics 2007;10: 177-87.

[24] Kessler RC, Ustun TB. The World Mental Health (WMH) Survey Initiative Version of the World Health Organization (WHO) Composite International Diagnostic Interview (CIDI). International Journal of Methods in Psychiatric Research 2004;13:93-121.

[25] Kessler RC, Heeringa S, Lakoma MD, Petukhova M, Rupp AE, Schoenbaum M, et al. Individual and societal effects of mental disorders on earnings in the United States: results from the national comorbidity survey replication. American Journal of Psychiatry 2008;165:703-11.

[26] Manning WG, Mullahy J. Estimating log models: to transform or not to transform? Journal of Health Economics 2001;20:461-94.

[27] Matchette RB, Danis JS. United States national archives. Guide to federal records in the national archives of the United States. Washington, DC: National Archives and Records Administration; 1995.

[28] Mechanic D, Bilder S, McAlpine D. Employing persons with serious mental disorders. New Brunswick, NJ: Rutgers University, Institute for Health, Health Care Policy, and Aging Research; 2002.

[29] Merikangas KR, Ames M, Cui L, Stang PE, Ustun TB, Von Korff M, et al. The impact of comorbidity of mental and physical conditions on role disability in the US adult household population. Archives of General Psychiatry 2007;64:1180-8.

[30] Murray CJL, Lopez AD. The global burden of disease: a comprehensive assessment of mortality and disability from diseases, injuries, and risk factors in 1990 and projected to 2020. Cambridge: Harvard School of Public Health; 1996.

[31] O'Neill DM, Bertollo DN. Work and earnings losses due to mental illness: perspectives from three national surveys. Administration and Policy in Mental Health 1998;25:505-23.

[32] Pennell BE, Mneimneh Z, Bowers A, Chardoul S, Wells JE, Viana MC, et al. Implementation of the World Mental Health surveys. In: Kessler RC, Üstün TB, editors. The World Mental Health survey initiative: patterns of mental illness in the WMH surveys, vol. 1. New York: Cambridge University Press; 2008. p. 33-57.

[33] Rice DP, Kelman S, Miller LS, Dunmeyer S. The economic costs of alcohol and drug abuse and mental illness: 1985. Washington DC: Department of Health and Human Services; 1990.

[34] Schempf A, Becker S. On the application of decomposition methods. American Journal of Public Health 2006;96:1899.

[35] Ware Jr JE, Kosinski M, Keller SD. A 12-item short-form health survey. Medical Care 1996;34:220-33.

[36] Wittchen HU. Reliability and validity studies of the WHO Composite International Diagnostic Interview (CIDI): a critical review. Journal of Psychiatric Research 1994;28:57-84.

[37] World Health Organization. Project atlas: resources for mental health and neurological disorders, $<$ http://www.who.int/globalatlas/dataQuery/default. asp >; 2008 [accessed August 19, 2008]. 